\title{
Ultrasound Enhanced Ferrite Plating
}

\author{
Y. Kitamoto, M. Zhang, S. Haijima, K. Matsumoto and M. Abe \\ Department of Physical Electronics, Tokyo Institute of Technology, O-okayama, Meguro-ku, Tokyo, 152, \\ Japan
}

\begin{abstract}
This paper is the first report of sonochemistry (or application of power ultrasound to stimulate chemical processes in liquids) combined with ferrite plating - a wet chemical method to synthesize ferrite films from aqueous solution. Due to the ultrasonic enhancement, we have successfully encapsulated polyacrylate spheres, $\sim 0.25 \mu \mathrm{m}$ in diameter, with magnetite in a aqueous solution of $\mathrm{FeCl}_{2}$ at $65^{\circ} \mathrm{C}$. This broke through the lower limit $(\sim 0.3 \mu \mathrm{m})$ of the size of the particles to be encapsulate with magnetite without applying the ultrasound waves. The magnetite coating has magnetization (92emu/g) which is the same value as that reported for bulk samples, being increased from that $(65 \mathrm{emu} / \mathrm{g})$ obtained without the ultrasonic enhancement.
\end{abstract}

\section{INTRODUCTION}

Sonochemistry, an application of power ultrasound to stimulate chemical processes in liquids, is currently the focus in a wide range of chemical materials science and technology, since it causes novel chemical and physical reactions which will never occur unless sonically stimulated. The power ultrasound generates in the liquids localized "hot spots" of extremely high temperatures $\sim 3000 \mathrm{~K}$ and high pressures $\sim 300$ atm due to collapse of cavitation bubbles, which activates not only chemical reactions but also dynamics of atoms during the chemical processes[1]. In this paper, we report that combining sonochemistry with ferrite plating improves microstructure and qualities of the films. We have successfully obtained continuous coating of $\mathrm{Fe}_{3} \mathrm{O}_{4}$ encapsulating polyacrylate microspheres smaller than $0.3 \mu \mathrm{m}$ in diameter, which was impossible by conventional ferrite plating without applying ultrasonic waves[2].

\section{EXPERIMENTAL}

As shown in Fig.1, ultrasonic waves $(19.5 \mathrm{kHz}, 600 \mathrm{~W})$ were applied by a horn $(30 \mathrm{~mm} \phi)$ to a reaction solution of $\mathrm{FeCl}_{2}$ at $65^{\circ} \mathrm{C}$ and $\mathrm{pH}=7$, in which polyacrylate microspheres, $0.25 \mu \mathrm{m}$ in average diameter, were dispersed as substrates for the $\mathrm{Fe}_{3} \mathrm{O}_{4}$ plating. $\mathrm{A} \mathrm{NaNO}_{2}$ solution was supplied to the solution to keep oxidation reduction potential (ORP) at a desired value, and $\mathrm{NH}_{4} \mathrm{OH}$ solution to keep the $\mathrm{pH}$ value. All the aqueous solutions have been deairated by bubbling $\mathrm{N}_{2}$ gas in the solutions before and during the plating. The coats were characterized by X-ray diffraction using $\mathrm{CuK} \alpha$ radiation and Mössbauer spectrometry using a ${ }^{57} \mathrm{Co}$ source at room temperature. Magnetic properties were measured by a vibrating sample magnetometer (VSM). Surface of the coating was observed by a field emission type scanning electron microscope (FE-SEM).

\section{RESULTS AND DISCUSSION}

Performing the reaction for 90 minutes, we obtained $\mathrm{Fe}_{3} \mathrm{O}_{4}$ coats, $0.1 \sim 0.13 \mu \mathrm{m}$ in thickness, which encapsulated the entire surface as shown in Fig.2. The coats were composed of grains, $50 \sim 100 \mathrm{~nm}$ in size, which were polycrystalline $\mathrm{Fe}_{3} \mathrm{O}_{4}$ with no impurity phase as results of the X-ray and Mössbauer analyses.

Saturation magnetization was $92 \mathrm{emu} / \mathrm{g}$ which is the same value as that reported for bulk $\mathrm{Fe}_{3} \mathrm{O}_{4}$ samples, which is larger than 
that $(65 \mathrm{emu} / \mathrm{g})$ of the continuous $\mathrm{Fe}_{3} \mathrm{O}_{4}$ coating on porous silica spheres of $1 \sim 3 \mu \mathrm{m}$ diameter without applying the ultrasonic waves[3]. Therefore, the ultrasonic waves enabled us to encapsulate the entire surface of the very small polymer spheres, and also improved crystallinity and microstructure of the magnetite coating.

Applying the power ultrasound activates migration of atoms on substrates. The improvements in the coating are attained because the activated migration suppresses the so-called "shadowing effect" which causes poor crystallinity and distinct columnar structure with voids when the migration is inactive, as is generally found in sputter-depositions at high working gas pressures[4].

\section{CONCLUDING REMARKS}

The sonochemical technology or the application of the power ultrasound broke through the lower limit $(\sim 0.3 \mu \mathrm{m})$ of polymer particle size to be encapsulated with continuous magnetite coat. The coat has magnetization ( $92 \mathrm{emu} / \mathrm{g}$, the same as bulk value) stronger than that $(65 \mathrm{emu} / \mathrm{g})$ obtained previously without the ultrasonic enhancement. When the ferrite-encapsulated spheres are applied to the carriers for the enzyme immunoassay (which has been put to practical clinical use utilizing the spheres with island-shaped ferrite coating), the sensitivity will increase much; the continuous coat has much wider surface area of ferrite and stronger magnetization than the island-shaped coat. Also, the novel ferrite capsulated spheres will improve the performances of other medical applications of magnetic fine particles, such as drug delivery, hyperthermia, and diagnostic contrast enhancement.

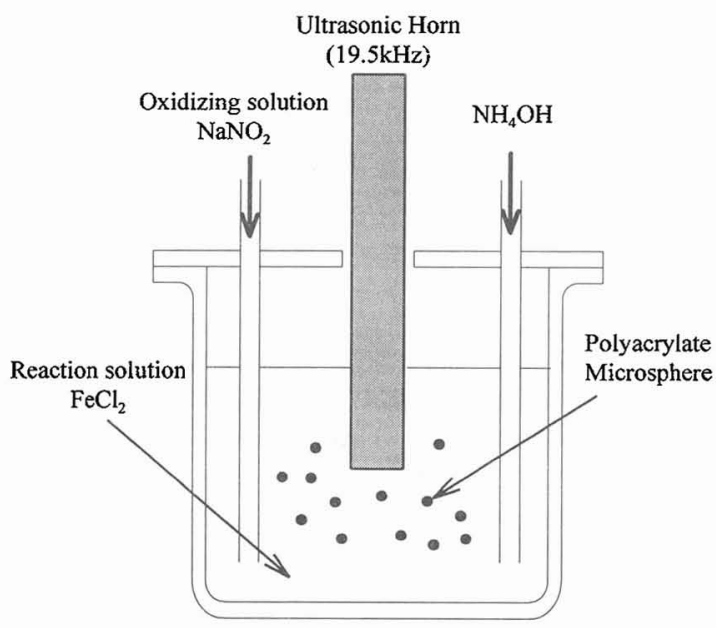

Fig. 1. Schematic illustration of ultrasound enhanced ferrite plating apparatus.

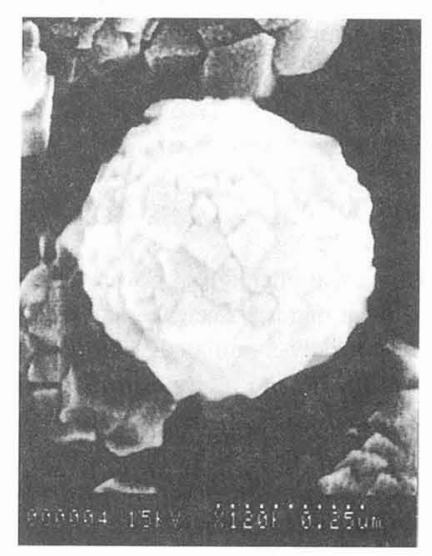

Fig. 2. SEM photograph of $\mathrm{Fe}_{3} \mathrm{O}_{4}$ coated polyacrylate microspheres.

\section{References}

[1] C. Sehgal, R. P. Steer, R. G. Sutherland, and R. E. Verrall, J. Chem. Phys., 70 (1979) 2242.

[2] S. Nagahata, M. Sasaki, K. Yoshioka, M. Anan, M. Abe, Proceedings of ICF-6, (1992) 279.

[3] M. Zhang, Q. Zhang, T. Itoh, and M. Abe, IEEE Trans. Magn., 30 (1994) 4692.

[4] J. A. Thornton, J. Vac. Sci. Technol., A4 (1986) 3059. 